\title{
The Impact of Social Media Big Data on Organizations
}

\author{
Yi Zhang, Lijun Chen, Xiaoru Chen \\ South China Institute of Software Engineering of Guang Zhou Universality, Guangzhou, 510990, China \\ E-mail: zy@sise.com.cn, 372158286@qq.com, 479170369@qq.com
}

\begin{abstract}
Social media is now an important form of online communication. Users can share their opinions, opinions and attitudes through Internet media platforms such as WeChat, QQ, Twitter, Facebook, Sina Weibo, etc., thus forming a huge political, economic, cultural, military and other fields of influence. Through social media-sponsored demonstrations, the color revolution and political struggle are becoming social activities that are hard to find on the Internet, creating potential social and government management risks that require specific technical means to monitor and manage social media platforms. The information on social networks is generated quickly and the amount of data is huge. At the same time, the scope of content dissemination has broken through the limitations of traditional media. The existing online public opinion monitoring system has been unable to meet the requirements of massive data collection, storage and analysis. In addition to government legislation and mobilization of public reporting, we also recommend the use of big data and artificial intelligence to promote scientific social governance.
\end{abstract}

Keywords—social media, big data;government, organizational influence, control methods

\section{INTRODUCTION}

Baidu Encyclopedia defines "social media" as: social media is a tool and platform for people to share opinions, opinions, experiences and opinions with each other. Currently mainly include social networking sites, QQ, WeChat, Weibo, blogs, podcasts, BBS, etc. The development of foreign social media has been more than 40 years old, dating back to the birth of the first e-mail in 1971 . Since the 21st century, especially since the founding of Facebook in 2004, social media has entered its heyday. China's social network has experienced nearly two decades of development. The social network began to develop from the PC side, entered a period of rapid growth in 2005, and entered a period of rapid development in 2010. According to iresearch, CNNIC data shows that as of June 2016, the number of China WeChat users has exceeded 650 million, and the mobile Internet has entered a relatively mature stage after years of development. The use of social media can shape politics, business, world culture, education, career, innovation and more.

This article describes the big data generated by social media and the application of social media in politics, business, education and other fields. We are also concerned about what steps should be taken to monitor QQ, WeChat, Facebook, Twitter and other social media so that social media can have a positive impact on the country and society.

\section{THE IMPACT OF SOCIAL MEDIA}

\section{A. The riots live on social media}

On December 19, 2016, 600 prisoners in a private prison in Birmingham, England, made a big news. They launched a riot! The prisoners started operations around 9 am local time and swept four positions.

At the beginning, there were keys for prisoners to steal prison guards and successfully entered the four positions in Victoria. After entering, they began to set fire, set fireworks, rushed to the prison guard's office to take batons and helmets, and destroyed the equipment in the prison. In the process of riots, the inmates used the stolen mobile phone to call the outside world, and took photos and uploaded them to social media to broadcast the riots online. Foreign affairs think that these prisoners are not trying to escape, but more about "selfentertainment", shown in Figure 1.

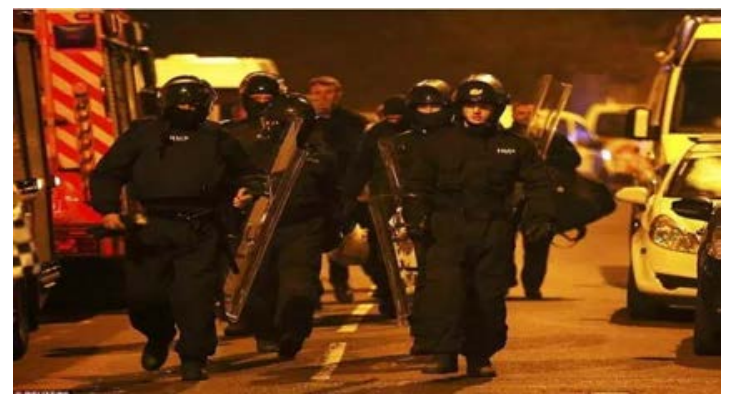

Figure 1: Inmates posted selfies on social media during the disturbance.

\section{B. Social media in Indonesia "fan the flames"}

[Asia-Pacific Daily News] A riot occurred in a city in North Sumatra, Indonesia, and many Buddhist temples were destroyed by rioters. Indonesian police said on the 31st that the riots were caused by people igniting on social media. The police are currently arresting nine suspects.

According to the Lianhe Zaobao, Indonesian National Police Chief Tito told the media after visiting the riot scene on the 31st that before the incident, a local Chinese woman was dissatisfied with a mosque and used a loudspeaker to broadcast to believers in front of his house. Pray and chanting calls to complain to the mosque. After the two sides could not talk about the results, they went to the police station in the city to be mediated by the police.

He said: "At the time of mediation, some people spread rumors on social media, causing public outrage and leading to riots." 
According to the Jakarta Post, the riots occurred on the evening of the 29th in the coastal city of Tanjong Bale, near the northern Indonesian city of Medan. A temple and three stupas were burnt down. The mob also smashed the Buddha statue and prayed. Supplies, tables, chairs, lamps, several cars and electric bicycles, and robbed the temple.

\section{Social media has sparked unrest in Iran}

In January 2018, riots broke out in various Iranian cities and quickly spread throughout the country. The Iranian government responded quickly, including blocking two social software used by protesters and restricting Internet access in certain areas. In 2009, there was a feeling of deja vu, when a young State Department official called his college classmate, the founder of Twitter, and postponed a 48-hour upgrade to ensure that protesters on the streets of Tehran could use social media to launch a The "revolution" was affected. In this context, Iranian officials immediately characterized the riots as "a copy of the 2009 Twitter Revolution”, accusing foreign agents of being infiltrated through social media as the main cause of the riots.

From the above facts, social media can have a profound impact on politics. A study found that $62 \%$ of the news came from social media. Social networks are helping the basic return of human society. Because social media allows people to communicate more freely with each other, it helps to build social organizations with amazing influence through social media in groups that have been marginalized.

Nearly $80 \%$ of Internet users are on social platforms. Because social networks promote human interaction, and because of the Internet, everyone with a marginal view can see that he is not alone. When these people find each other through social media, they can do something without social media, social, moral, environmental and political ills. Increasing awareness has shifted the balance of power from a minority to the masses. While social media activities raise awareness of social issues, there is doubt as to whether this awareness will translate into real change.

The company recognizes the importance of using social media to connect with customers and increase revenue. Companies have realized that they can use social media to generate insight, stimulate demand and create targeted products. Many studies have shown that implementing social networks in the workplace can enhance knowledge sharing. The result is improved communication of project management activities and expertise. Full implementation of social technologies in the workplace can eliminate boundaries, eliminate silos, improve interaction, and help develop highly skilled and knowledgeable employees.

Social media has had a profound impact on recruitment. $19 \%$ of hiring managers make hiring decisions based on information on social media. According to the survey, $60 \%$ of employers use social networking sites to research job seekers.

One of the roles of social media is to encourage people to build and cherish human connections with true friendships. The word "friends" used on social media lacks the intimate relationship defined by traditional friendships. In this traditional friendship, people actually know each other, want to talk, have intimate relationships and often face to face. Information is power. Without the means of information transmission, people cannot use this power. A positive aspect of social media is the spread of information in today's world. Without social media, the world will slow down and the emergence of social media will bring many benefits. As a result, social disruption has also produced a large amount of disorderly big data. We need to use big data technology to mine useful things, to make social big data move in a favorable direction, and to suppress adverse effects

\section{BIG DATA AND SOCIAL MEDIA}

\section{A. Social media}

Social media refers to a communication platform based on Internet user relationships, and is a tool for people to share opinions, opinions, experiences and opinions. It comes in many forms, including QQ, WeChat, social networking sites, Weibo, blogs, BBS, etc [1].

\section{B. Social media types and analysis}

According to kantar's 2017 China Social Media Impact Report released in Beijing. The results show that respondents generally have a positive attitude towards social media and believe that social media makes their lives better. A new survey this year showed that people's impact on social life's impact on their lives was 79.8 points. By age, the negative impact of the post-90s on social media is even stronger. In the fourth consecutive year of kantar's China Social Media Impact Report, social media is divided into nine sub-categories and respondents are asked to rate the subcategories they use [2].

Chinese social media user data shows that due to the dominant position of WeChat, it is being investigated as a separate sub-category. WeChat scored a top score of 83.5 in 9 subcategories. WeChat scores are high based on age, gender, and city level. Life service social media (such as dianping, ctrip, meituan, qunar) scored the second highest score of 81.7, and the social function score of the ecommerce platform ranked third (81.2). Due to the rise of WeChat, Weibo has been rebounded by users and stock prices. The survey shows that the younger the group, the higher their score on Weibo. After the 1990s, he scored 79.3 points on Weibo.

The behavioral data in this report also found that the microblog penetration rate reached $35.7 \%$ in April, an increase of 3.7 percentage points over the same period of last year, while the young users aged between 18 and 25 jumped 13.7 percentage points to $45.9 \%$ [ 3 ].

With the diversity of social media platforms, brands should focus on different platforms of different generations to achieve better touch results. "In order to thrive in a turbulent virtual social world, content that emphasizes content and quality tends to attract people's hearts," said Kantar Vermeer, director of strategic consulting. Before consumers take proactive steps to prevent social media push functionality, brands need to operate more carefully to find the right platform and the right time node to attract the right consumers with the right information.

The most common positive impacts of social media are the social connections and knowledge acquisition of acquaintances, such as "getting to know the dynamics of friends" (70\%) and "making it easier for me to communicate with my family/friends” (70\%), “ Help me understand social 
hotspots faster (69\%) and "increase my knowledge" (61\%) [4].

Overall, young people are more vigilant about the negative impact of social media. For example, the post-90s generation of "social media made me feel emptiness and impetuous" (31\%), "unable to concentrate" (34\%) and "affected by negative value" had the highest rate of mention (29\%). They are also more willing to take decisive measures to curb the negative effects of social media: $39 \%$ of those born in the 1990s said they have closed social media push notifications [5].

Maximizing customer understanding is the foundation of a company's prosperity. Therefore, monitoring people's online behavior is very important to their success. Agents are investing in such analytics to make Big Data a key component in monitoring social media campaigns, especially on social networking sites such as WeChat, QQ, Facebook, Twitter and LinkedIn.

Social media analytics is a synthesis of Internet user behavior. The availability of data such as consumer web browsing, online shopping behavior, customer feedback and social networking marketing research enables companies to understand consumers in a timely and broad manner. As a result, companies can pool market intelligence strategies based on different objectives (such as advertising and product launches); promote brands; increase customer loyalty; provide personalized services to customers; understand market trends and competitors; and minimize risk-expanding business.

\begin{tabular}{|c|c|c|c|c|c|c|c|}
\hline $\begin{array}{l}\text { Yeo } \\
\text { Rank }\end{array}$ & Domain & & TrustGauge & Company Name & Links $\rho$ & $\begin{array}{l}\text { Cateoory } \\
\text { Rank }\end{array}$ & (D) \\
\hline 1 & google.com & (rivirio) & 7 & Google & $73,879,305$ & FF & 1 \\
\hline 2 & youtube.com & 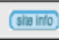 & 7 & YouTube, Inc. & $270,851,345$ & $6 \vec{F}$ & 1 \\
\hline 3 & facebook.com & (ivirto & 10 & Facebook & $2,431,198$ & B $\vec{F}$ & 2 \\
\hline 4 & yaloo.com & (mintion, & 10 & Yatroo! linc. & $56,691,947$ & 7 F & 1 \\
\hline 5 & wikipedia.org & 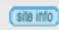 & 8 & Wíkinedia Foundation & $17,283,254$ & 4 랍 & 1 \\
\hline 6 & Iive.com & (sintion & 7 & NAA & $208,439,792$ & $2] F$ & 1 \\
\hline 7 & amazon.coum & (6rinto) & 7 & Amiazon.com & $157,027,170$ & Fif & 1 \\
\hline 8 & msn.coun & (mino, & 10 & Microson Corp & $32,962,554$ & 4 톱 & 2 \\
\hline 9 & bingcom & (manto & 6 & NAA & 0 & 0 & \\
\hline 10 & blouspol.com & 5 & 7 & Daniel Springer music & $517,021,582$ & 2 랃 & 1 \\
\hline
\end{tabular}

Figure 2: Historical traffic trends for the two websites from November 10 , 2017 to November 11, 2018

The big data phenomenon applied to social media is driving a new and growing field of research - "emotional analysis." Its purpose is to understand what people say or share in their daily lives. Companies mine this information to understand their customers and improve their operations accordingly. Educational institutions can also "listen" to students' opinions and learn more about their views. Through student activities on social networking sites, sentiment analysis provides a useful tool to gather information about their online behavior and, most importantly, their feedback on different aspects of the education system, such as college admissions, qualifications, exams and their ambition.

Companies can use this information to develop marketing strategies. This can be done in a variety of ways, such as monitoring country online exams to monitor their exam experience, understanding what their brand means for students, and getting feedback on new products for countries with lower-than-expected online activities

\section{Mining Social Media Big Data}

Let's take a disaster as an example to show how to mine social big data:

In recent years, social media has evolved from passive information collection tools to disaster management tools in emergencies, with multiple functions, such as disseminating real-time warning information, receiving requests for assistance, and responding to specific situations. The data mining application of social media mainly includes the following four aspects.

\section{A. Disaster perception and information coding}

Disaster perception describes the process of understanding what is happening in a particular affected area in an event involving multiple participants and variables. In research, it is often emphasized that geographical location is perceived as "what is happening in a particular space”.

With the help of interactive internet terminals, social media users can post location information through geographic coordinates to report on events that they are experiencing or are witnessing. For example, bridges and roads are blocked, settlements or donation sites are closed. Information about the location and place names displayed in the published message can be used to identify the extent of infrastructure damage, the extent of personnel disasters, and the identification of evacuation areas and resource scarce areas.

The diversity of information disseminated and shared through social media networks makes it necessary to classify information and create maps that reflect the situation before disaster perception. For example, during the typhoon Bopha, using a tiny crisis management platform, tweets were spontaneously broken down into topics such as casualties, vehicle damage, building damage and flooding. The disaster situation map is based on this information for future help. At the same time, the concept of information communication about Backchannel has also been proposed. In addition, information about casualties, donations, and disaster warnings may be used to improve real-time situational awareness to help extract reliable data from disaster response and recovery processes. However, the limitation of these coding methods is that they may not provide enough information about events before and after a disaster.

\section{B. Event detection and tracking}

Network communication of communication media has become a very competitive way of obtaining information with its unique low cost advantage. For example, Twitter has more than 190 million registered users and publishes more than 55 million messages a day. On July 6, 2013, the Asian Airlines 214 from San Francisco International Airport in Seoul, South Korea crashed. Witnesses posted pictures of black smoke on the Internet, quickly spreading disaster information to social media and immediately became world famous.

The speed and timeliness of social media dissemination of information makes it widely used in the detection process of events. Its main functions include: obtaining spatial 
information, obtaining reliable sources of disasters, and focusing on the impact of disasters on specific populations.

For example, there is a correlation between the dynamics of information published on Twitter and earthquake disasters. This study uses regression analysis to find out the center of the event occurrence and development trajectory, and establish a space-time model. For example, by tracking Twitter information, researchers can also understand people's attitudes toward swine flu and measure the spread of the virus. The number of flu cases from Twitter users accurately assesses the level of infectious disease, indicating that information from social media can be used as a means of protecting the public interest or promoting public health. In other cases, by collecting and collating fire information in multiple social networks, regression analysis is used to infer possible communities. In another case, research on Hurricane Irene showed that the number of tweets is related to the peak of the event, the location of the event, and the gender of the user. The study found that women are more concerned about the crisis.

\section{Disaster relief}

When a disaster strikes, aid workers inevitably lag behind the affected victims when they arrive at the scene, making the locals the most active information provider. In fact, the contribution of witnesses or people affected by disasters to relief has been widely recognized. For example, the Humanitarian Aid and Disaster Relief Organization (HADR) has begun extracting valuable data from social media data.

This has led to an increasing focus on social media data in disaster relief. To better help organizations track, analyze, and monitor information on WeChat, Kumar has developed powerful tools for data analysis and visualization - real-time status, data compression and historical review - and hopes to improve disaster response. Hwi-chi koh reviewed the strengths and weaknesses of social media in disaster relief applications and discussed the challenges that the model faces in enhancing disaster coordination, accuracy and safety.

Recent research has also shown that actionable data can be extracted from social media information, which can help emergency workers take quick action. For example, Ashtrabi launched "Tweedr," an information mining tool that helps relief workers extract useful information about rescue. The system consists of three main components: classification, clustering and extraction. As another example, prusitt proposed a set of methods for automatic identification and matching requirements to achieve supply and demand relationships and matching of goods and services.

Therefore, social media data analysis and visualization can be used for disaster relief, providing effective assistance and support for the automatic identification of the time, location, extent and object of the disaster

\section{Damage assessment}

For urban areas suffering from disasters and emergencies, the first priority is to assess casualties and property damage. Accurate disaster assessment helps coordinate future evacuation and rescue operations. Currently, remote sensing satellites have become a common means of disaster assessment because they can collect large amounts of dynamic and spatiotemporal data. However, depending on the instrument or platform, massive amounts of data based on remote sensing may not be fully functional. Therefore, spontaneous geographic data (VGI: Voluntary Geographic Information) can be used as a useful complement to traditional remote sensing data. For example, the tool can be used to estimate roads affected by flooding. In this work, various unofficial multi-source data, such as Weibo, Google Street View photos and geographic information, monitoring traffic flow information in the detection, Youtube and news, can be used to help assess the extent of the disaster. In addition, social media data can help people understand social perspectives or emotional trends and extract useful information to help with disaster relief. Disaster assessment itself takes a long time and a lot of manpower and material resources. After a disaster, people must choose between speed and accuracy, which fully reflects the advantages of social big data - the cost of collecting and analyzing this data is much lower than traditional data. If scientific classification and induction can be achieved, it can effectively assist in the development of disaster relief.

\section{TOOLS AND METRICS}

The role of social media in social movements and political transformation in countries such as Egypt and Turkey has made Beijing aware of the need for Internet censorship. While investing a lot of resources in Internet censorship, we are aware of the importance of new media. The Chinese government is trying to figure out how to use these new media tools.

Government departments have begun to set up official Weibo and blogs, and there are currently about 2 million online commentators. They don't want social media to be a tool for people to express dissatisfaction with the government. They want to use the same tools to spread information. For example, the Jinan Intermediate People's Court of Shandong Province published information on the BXL case on the official Weibo in August. The Chinese government website hosted by the General Office of the State Council also launched official Weibo and WeChat in October.

Social media plays an active role in exposing official corruption. For example, netizens exposed Lei Zhengfu and other officials on Weibo. On the one hand, it provides a new platform for the central government to supervise local governments to obtain information and public opinion, and on the other hand, it provides a new channel for expression.

According to official Chinese statistics, the number of Weibo users has exceeded 300 million, and the number of WeChat users has exceeded 300 million. With the increasing popularity of social media, the Chinese government has become increasingly strict in controlling and reviewing social media. On the other hand, the Chinese government has also seen the importance of social media as a public relations platform.

Since social media can play an important role in various parts of the country and society, some are positive and some are side effects. Let us use the government as an example to understand how the government monitors social media. 


\section{A. Major measures of social media management in foreign countries}

Social media has developed rapidly in recent years and has become an indispensable part of people's daily lives. At the same time, there have been many unfavorable factors. Countries have adopted relevant policies and adopted various measures to manage them. There are many effective methods, but there are also lessons for failure. This article takes the United States, Germany and South Korea as examples to explore the main measures of foreign social media management and summarizes the effective experience.

\section{1) The United States:}

The United States does not have a dedicated network police, but through the establishment of detailed laws, the establishment of specialized law enforcement agencies, mobilize joint action of various departments, encourage the public to actively report, and its various law enforcement agencies can be said to be network police

\section{2) Germany:}

Work with the EU to provide strong execution. According to a survey by information security provider McAfee and US think tank CSIS, cybercrime caused Germany's GDP loss to be $1.6 \%$ of GDP. As a member of the European Union, Germany has worked with other member states to develop measures for internal management of social media. (1) Cooperate with the EU to formulate laws and regulations and strengthen law enforcement. (2) The real name system is combined with industry selfdiscipline. Germany requires Internet companies to conduct industrial self-discipline and Internet users for moral selfdiscipline. For example, Google invites users to jointly monitor information and report illegal and undesirable information in their website statements. Once the report is received, Google will review and delete the content

\section{3) South Korea:}

Use a variety of measures to combat cybercrime. Online rumors about politics and the economy are common in South Korea, some affect people's judgments, and others threaten social stability. Currently, seven departments that oversee the Korean Internet and new media communications include the Ministry of Culture, Sports and Tourism, the Broadcasting and Communications Commission, and the Department of Security and Administration. (1) Real name system. In December 2006, South Korea passed the Internet Real Name System, requiring Internet users to register their real names and ID numbers and pass verification before they can post and follow posts on various websites. (2) The police station set up a special search. South Korea first set up a computer crime investigation team under the police station in 1997, and then set up a cyber terrorist attack response center. In June 2014, the Cyber Security Bureau of the Korean National Police Agency officially became

\section{B. China's measures for social media monitoring}

China's social media is in a period of rapid development, and there is still much room for development in the future. Drawing on domestic and foreign experiences and lessons, drawing on each other's advantages, China's regulatory measures are more in line with national conditions; the combination of natural law and law, relaxation and moderation, promoted the development of social media.

1) Establish and improve the social media supervision legal system. Legislation is the foundation of governance. Appropriate laws and regulations should be introduced and managed in accordance with the actual situation in China.

2) Multi-pronged approach, joint supervision. The management measures of the United States, Germany and the Republic of Korea are multifaceted rather than relying on a single category of measures.

3) Industry self-discipline, user awareness. In addition to external supervision, internal self-regulation is also an important means of managing social media networks.

4) Mandatory: All social media (such as QQ, WeChat, Weibo and other social media tools) must filter out government sensitive keywords such as Falun Gong, the Communist Party of China, and socialism before releasing information. Prevent publishers from posting information using these keywords.

5) Use big data technology to mine big data generated by social media, remove sensitive information that is not conducive to the government, and avoid social unrest caused by rumors.

6) The government should work with social media companies to empower government law enforcement agencies to operate relevant information.

\section{Tools for social media monitoring}

Monitoring social media, in addition to government legislation, can also filter keywords, mobilize public reports, we can also use some tools, such as: Yomego, Ubervu, Hootsuite and Vocus. Other tools that social media managers may use are shown in Tables 1 and 2. Table 1 lists the web analytics reporting tools that can be used to generate insights from users' own websites. Data is visualized through graphs and tables and can be customized through the dashboard. Table 2 provides a network traffic estimation service to help collect traffic to your website.

TABLE I WEB ANALYTICS TOOLS

\begin{tabular}{lll}
\hline Service & Description & URL \\
\hline $\begin{array}{l}\text { Google } \\
\text { Analytics }\end{array}$ & $\begin{array}{l}\text { Perhaps the most widely used } \\
\text { website metrics service. It } \\
\text { generates detailed metrics about } \\
\text { a website's traffic. It's easy to use } \\
\text { and is specifically designed for } \\
\text { marketing research. }\end{array}$ \\
\hline AWStats & $\begin{array}{l}\text { An open source web analytics } \\
\text { reporting tool where users are } \\
\text { encouraged to contribute to its } \\
\text { development. }\end{array}$ \\
\hline
\end{tabular}

TABLE II WEB TRAFFC ESTIMATION TOOLS

\begin{tabular}{ll}
\hline Service & Description \\
\hline Alexa & $\begin{array}{l}\text { Provides an estimate of the } \\
\text { percentage of internet users that } \\
\text { may have visited a website during } \\
\text { the last six months and allows } \\
\text { comparisons with other websites. }\end{array}$ \\
\hline Compete & $\begin{array}{l}\text { Helps to monitor online } \\
\text { competition and to benchmark } \\
\text { performance against the industry. }\end{array}$
\end{tabular}


While this data may not be completely accurate, it can be very useful to get an overview of market research.

\section{DISCUSSION}

Social media has developed rapidly in recent years and has become an indispensable part of people's daily lives. At the same time, there have been many unfavorable factors. Countries have adopted relevant policies and adopted various measures to manage them. There are many effective methods, but there are also lessons for failure. We also recommend that in addition to traditional social media monitoring methods, new technologies such as big data technology and artificial intelligence technology should be used to detect or prevent the spread of bad information according to the characteristics of social media.

\section{ACKNOWLEDGMENT}

Fund Project 1: Guangdong Province wisdom Museum mobile application public service platform (Fund code: 2015KTSCX176)

Fund Project 2: Guangdong Province Promotes Service Trade Innovation and Development Project (Fund code:

\section{CJ201804)}

Fund Project 3: Provincial Special Finance Fund for "Innovation and Strong School Project" in 2018(Fund code: SYJG201803).

\section{REFERENCES}

[1] British Broadcasting Corporation (BBC) (2017). Big Data Era: BBC Vision. Get it from http://www.youtube.com/watch?v=CO2mGny6fFs

[2] Big data (2016). Big data public and private forum. Get it from http://big-project. Yu Baier, m.a. , \& Laney, D. (2017). The Importance of "Big Data": A Definition (Gartner Report G00235055). Obtained https://www.gartner.com/doc/2057415?ref=clientFriendlyURL

[3] Bradbury, D. (June 2017). Effective social media analysis. "Guardian". Effective social media analysis from http://www.theguardian.com/technology/2013/6/10/

[4] Einav, L. \& Levin, J.D. (2017). Data Revolution and Economic Analysis 19035). Obtained from http://www.nber.org/papers/w19035

[5] Written (2017). Big data analysis. Labor and Skill Needs Assessment, 2012-2017 (E-skills UK on behalf of SAS UK report). Obtained from https://www.e-

skills.com/Documents/Research/General/BigDataAnalytics_Report_J an2013.pdf 